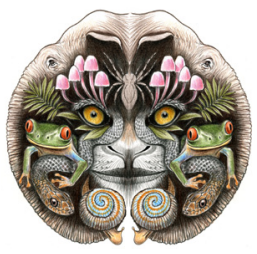

SSN 0974-7907 (Online) ISSN 0974-7893 (Print)

OPEN ACCESS

\title{
THE NESTING SUCCESS OF THE ORIENTAL DARTER ANHINGA MELANOGASTER (AVES: SUlIfORMES: ANHINGIDAE) IN THE YAMUNA BIOdIVERSITY PARK, NEW DELHI, INDIA
}

\section{S.L. Niangthianhoi ${ }^{1} \&$ Faiyaz A. Khudsar ${ }^{2}$}

${ }^{1,2}$ Yamuna Biodiversity Park, CEMDE, Department of Environmental Studies, University of Delhi, New Delhi 110007, India ${ }^{1}$ niangsl@gmail.com, ${ }^{2}$ faiyazwild@gmail.com (corresponding author)

Abstract: The Oriental Darter Anhinga melanogaster is a globally Near Threatened species that has been breeding in the Yamuna Biodiversity Park, Delhi since 2006. This is a recently restored site with the help of plant species assemblage in the form of plant communities of the Yamuna River basin and restoration of wetland ecosystems. A study was carried out during the nesting period of 2011 to assess the nesting success of the Oriental Darter in the park. A total of eight out of the nine incubated nests $(88.88 \%)$ were successful with hatchlings and one was abandoned within three weeks of incubation. An average of 2.87 chicks hatched per nest with 2.1 fledglings per nest. The males fed the nestlings more than the females during the study hours. The restored landscape, the Yamuna Biodiversity Park and its wetlands provide a suitable habitat for supporting the breeding population of many important birds including the Darter due to the availability of prey species, vegetation for roosting and nesting, and low disturbance leading to optimization of nesting of the Darters.

Keywords: Darter, ecological restoration, floodplain, nesting success, wetland, Yamuna Biodiversity Park.
Water pollution, loss of wetland and life-supporting riverine ecosystems in urban setups is a global issue and loss of habitat in urban areas of India has led to a population decline of many species of birds (Urfi 2006). Anthropogenic disturbances not only create problems for the various trophic levels of the ecosystem but also affect the ecosystem functioning, ultimately leading to the habitat loss resulting in the local extinction of many species. The Oriental Darter Anhinga melanogaster (henceforth Darter) is an important bird species of the Indian wetlands, belonging to the family Anhingidae of the order Pelecaniformes. Out of the four living species found in the world, namely, American Anhinga Anhinga anhinga, African Darter Anhinga rufa, Australian Darter Anhinga novaehollandiae and Oriental Darter Anhinga melanogaster (Alvarenga \& Guilherme 2003),
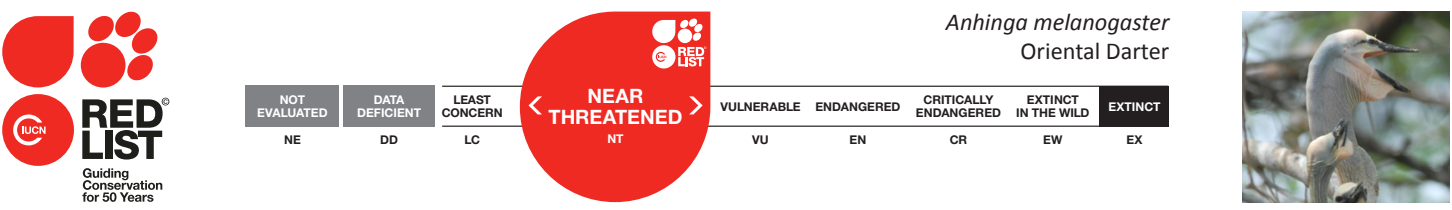

DOI: http://dx.doi.org/10.11609/jott.2430.7.14.8148-8153

Editor: C. Srinivasulu, Osmania University, Hyderabad, Telangana.

Date of publication: 26 November 2015 (online \& print)

Manuscript details: Ms \# 04001 | Received 17 April 2014 | Final received 02 November 2015 | Finally accepted 10 November 2015

Citation: Niangthianhoi, S.L. \& F.A. Khudsar (2015). The nesting success of the Oriental Darter Anhinga melanogaster (Aves: Suliformes: Anhingidae) in the Yamuna Biodiversity Park, New Delhi, India. Journal of Threatened Taxa 7(14): 8148-8153; http://dx.doi.org/10.11609/jott.2430.7.14.8148-8153

Copyright: (C Niangthianhoi \& Khudsar 2015. Creative Commons Attribution 4.0 International License. JoTT allows unrestricted use of this article in any medium, reproduction and distribution by providing adequate credit to the authors and the source of publication.

Funding: It is a joint collaborative programme of Delhi Development Authority and CEMDE, Delhi University.

Conflict of Interest: The authors declare no competing interests.

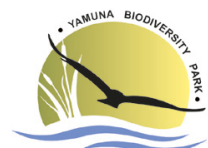

Acknowledgements: We thank our colleagues Dr. A.K. Singh, Dr. Ekta Khurana, Mohammad Faisal and Mohan Singh for sharing their knowledge and for their co-operation. 
it is the only species listed as globally Near Threatened by the Birdlife International (2012) since 2004 with a population estimated at 22,000 mature individuals and trend declining. In India, it is legally protected under Schedule IV of the Indian Wildlife (Protection) Act, 1972. The basic breeding ecology of the Darter in India has been previously documented from various heronries occurring in many wetlands (Pathak et al. 2004; Narayanan \& Vijayan 2007; Chozhiyattel 2009; Gopi 2010; Gopi \& 2011; Jha 2012), but none has been reported in recent years from Delhi, despite the species being a known breeding resident (Tak \& Sati 1997). The species is an obligate piscivore that prefers to forage in shallow water of less than (<) 5 m (Ryan 2007). The nesting of the Darter was not reported in and around the study area before the establishment of the Yamuna Biodiversity Park (YBP) (Urfi 2006). However, Darters have been nesting year after year since 2006 in YBP. So, this paper attempts to report scientifically relevant observations regarding the nesting ecology of Darter in YBP for the nesting period of 2011. The establishment of the YBP, Delhi in 2002, a restored area in the Yamuna floodplain, allowed observations of nesting ecology of Darters that used this park for breeding.

\section{STUdY AREA}

The present study was conducted in Yamuna Biodiversity Park, situated at $28^{\circ} 44^{\prime} \mathrm{N}$ and $77^{\circ} 12^{\prime} \mathrm{E}$ on the west-bank floodplains of the Yamuna River in Delhi (Fig. 1), a joint collaborative programme of Delhi Development Authority and CEMDE, Delhi University. An area of 185ha of degraded land with heavily silted marshes was taken up for the establishment of YBP with objectives to restore the riparian and wetland communities of the Yamuna River Basin using applicable ecological restoration principles. Based on various interventions during the restoration process in YBP the new concept of Biodiversity Park was defined, which is now being initiated in many parts of India such as Gurgaon, Haryana and Bangalore, Karnataka. A Biodiversity Park is, thus, defined as "a designated area with an assemblage of species in the form of biotic communities belonging to the particular ecological range which can perform the necessary ecosystem functions including conservation, education and recreation values".

About 64ha of this area is located in the inactive floodplain, which was cut-off due to an embankment where the entire area was highly saline with $\mathrm{pH}$ upto 9.2. The remaining 121 ha is still in the active flood-zone which is flooded annually connected with a corridor. Various forest communities were established based on

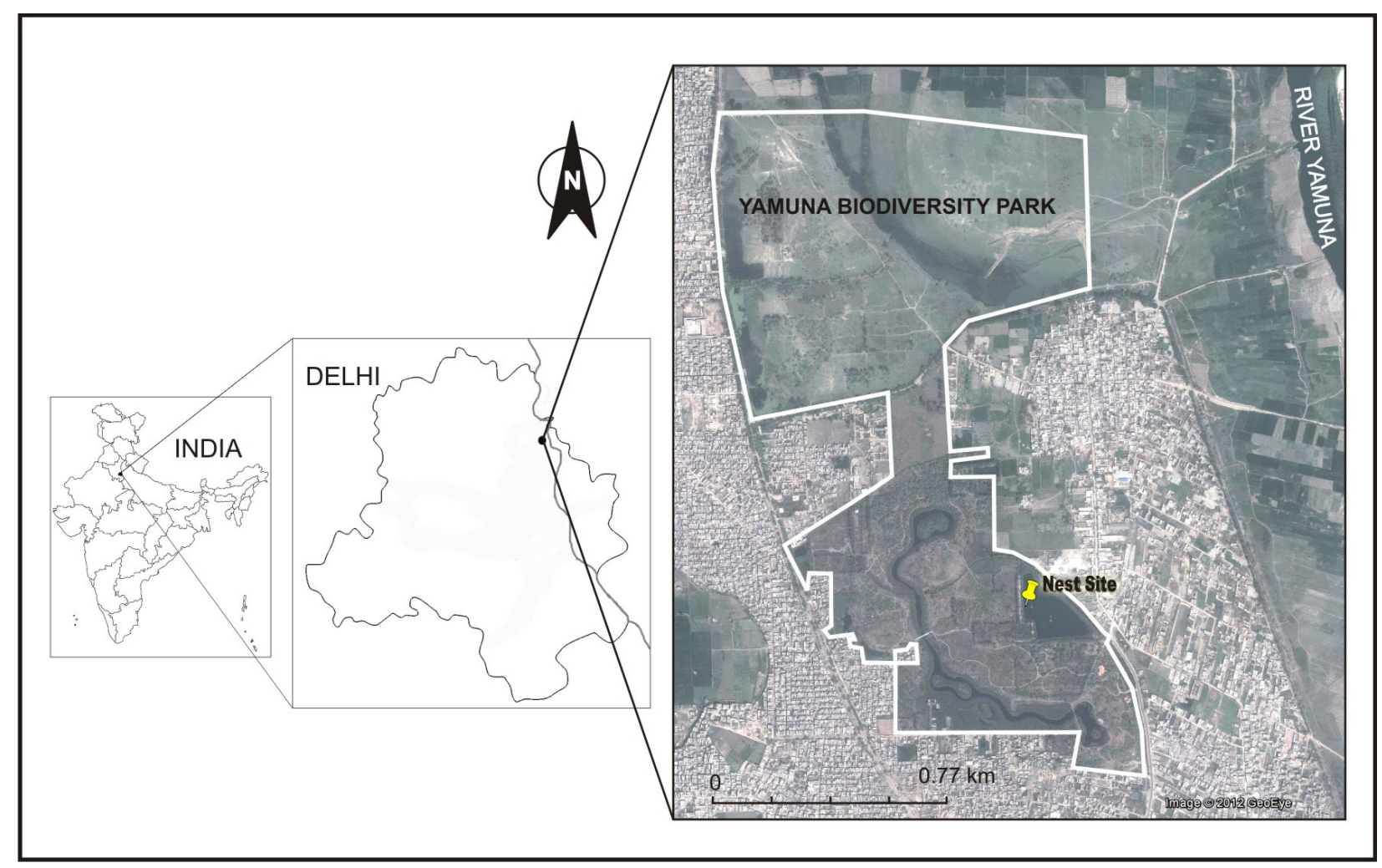

Figure 1. Map of Yamuna Biodiversity Park showing the nesting site. The insets show the locations of YBP in Delhi and Delhi in India. 
the existing reference ecosystems in the entire Yamuna floodplain along with desilting of wetlands which is now functional by rainwater harvesting and sub-soil water. Islands were created in the middle around the existing trees of Acacia nilotica to accommodate the nesting of birds. The existing row of Eucalyptus tereticornis was retained to facilitate nesting and roosting of birds.

\section{METHODS}

Observations began from 18 February to 25 August 2011, with the first nest making and ended until the fledging of all nestlings. It consisted of about 120 hours of field time spread over six months. The nest sites were visited three times a week between 10:00-11:00 $\mathrm{hr}$ and again between 15:30-16:30 hr. The nests were monitored using binoculars and field scopes from a $6 \mathrm{~m}$ high platform built $30 \mathrm{~m}$ from the nest trees. Extensive photography was also done throughout the study period to support the gaps in observations (Images 1-3). Field records and photographs of Darter nesting since 2006 were used to compile a data of successful nesting and compared with the present study. The girth at breast height $(\mathrm{GBH})$ of nest trees and nest heights were measured using a measuring tape and a rangefinder (Nikon rangefinder Laser 550) respectively.

Invasive nest checking was not done and clutch size was not determined to avoid disturbance. Initiation of incubation was noted from continuous sitting of adult birds. Nesting and fledging success was calculated based on observations of incubated nests. All relevant observations like days taken for nest completion, nest heights, success, role of male and female during incubation and feeding of nestlings were then analyzed statistically using MS Excel software. Gender contribution was determined from initiation of incubation to fledging of chicks to assess the role played by the adult birds during the study hours. The mean of these data are presented with standard deviation (SD).

\section{RESULTS}

The nesting of the Darter has been observed since 2006 on these trees in one of the wetlands with an area of about 2.5ha and varying depths of $2.4 \mathrm{~m}$ (dry season) and $4 \mathrm{~m}$ (post-monsoon). The restored wetland now supports dense aquatic vegetation along with many aquatic insects (Niangthianhoi \& Khudsar 2009), planktons (Ramaswami 2006) and fishes, surrounded by trees, grasses and sedges. It attracts thousands of migratory waders and ducks during the winter every year and supports the breeding population of many resident species. Nests of Darter were seen on Acacia

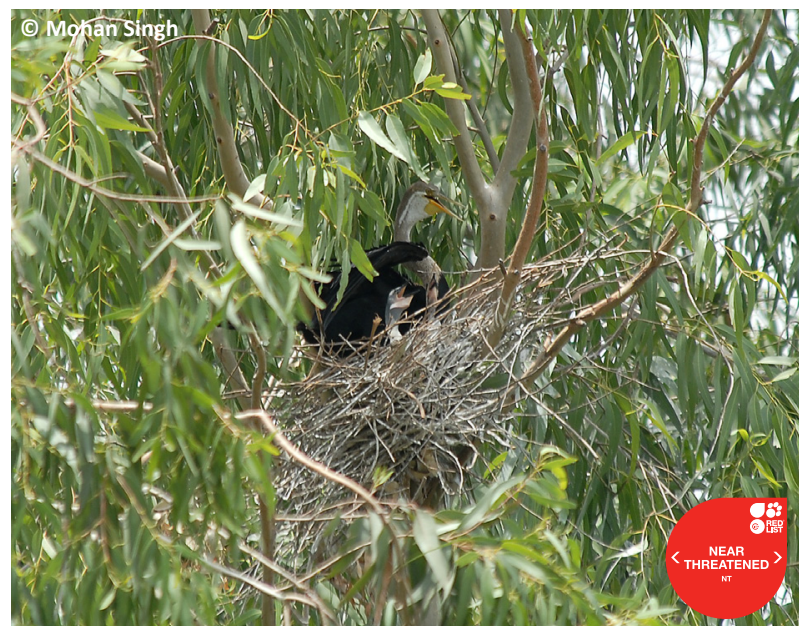

Image 1. An adult Oriental Darter Anhinga melanogaster with nestlings on a Eucalyptus tree in Yamuna Biodiversity Park, Delhi.

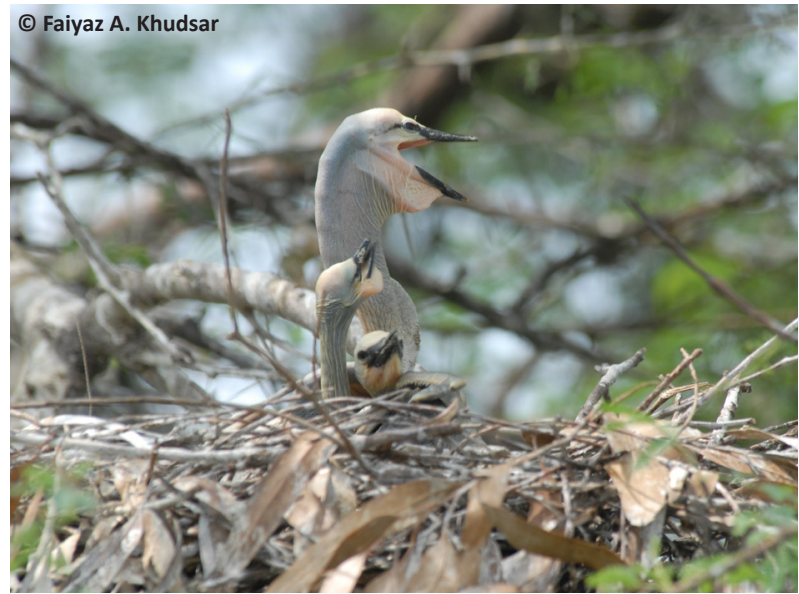

Image 2. Oriental Darter Anhinga melanogaster chicks less than two weeks old

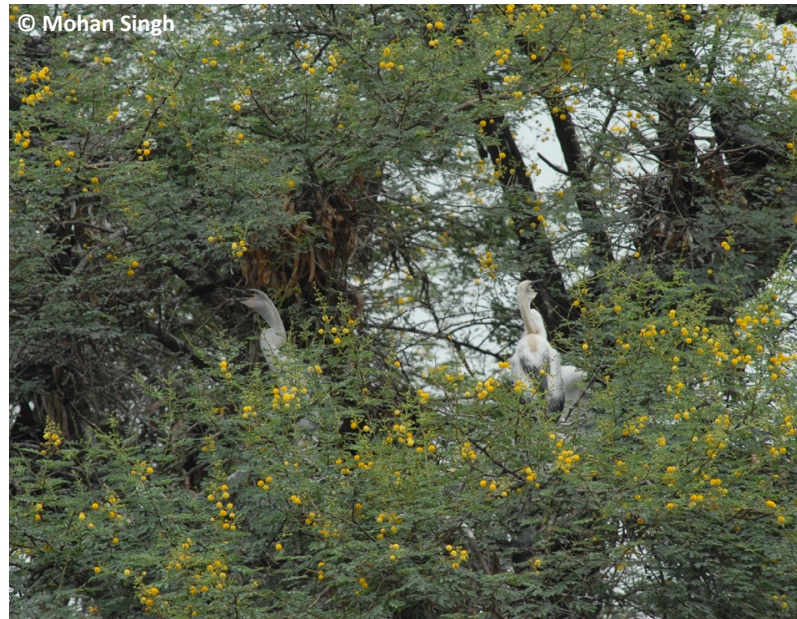

Image 3. A Young Oriental Darter Anhinga melanogaster of about five weeks old 


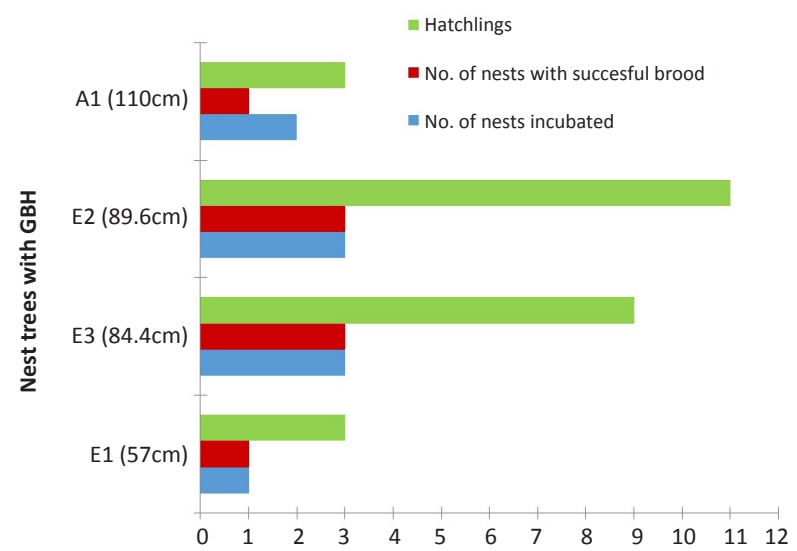

Figure 2. Different nest attributes on nest trees showing GBH

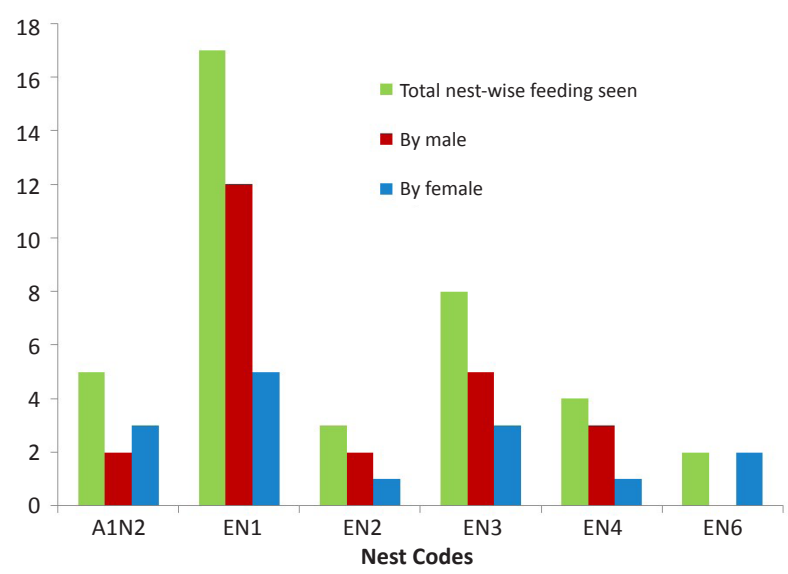

Figure 4. Sex-role differences in nest-wise nestling feeding

nilotica in the wetland as well as Eucalyptus trees around it in 2011. During the study period, the nest of the Little Cormorant Microcarbo niger and Pond Heron Ardeola grayii were observed on the neighbouring branches of Acacia nilotica. No predator activity was observed during the study period.

The total nest-occupancy period (from nest building to total fledging) of the Darter in 2011 in YBP lasted for 189 days spanning 10-14 weeks for each nest. A total of nine nests were incubated but only eight were successful with hatchlings. The nests $(n=9)$ were completed in $5.33 \pm 1.65$ days. Nests were built at the forking of big branches or closer to the main trunks of trees of Acacia nilotica and Eucalyptus tereticornis with a mean GBH of $92.2 \pm 24.47$ (SD) cm ( $=4$ ) (Fig. 2). Nest materials consisted mainly of dry and fresh twigs with leaves of Eucalyptus and some dry twigs of Acacia. The mean height of nests above the water on Acacia tree was $670 \pm 44.72 \mathrm{~cm}(\mathrm{n}=2)$, whereas the mean nest height above the ground on Eucalyptus trees was $1344 \pm 127.45$

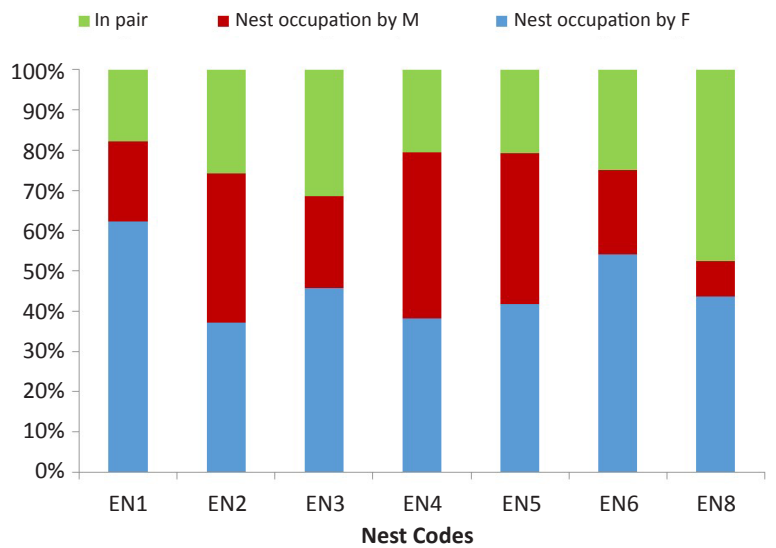

Figure 3. Sex-role in parental care during incubation till chicks venture out of nest

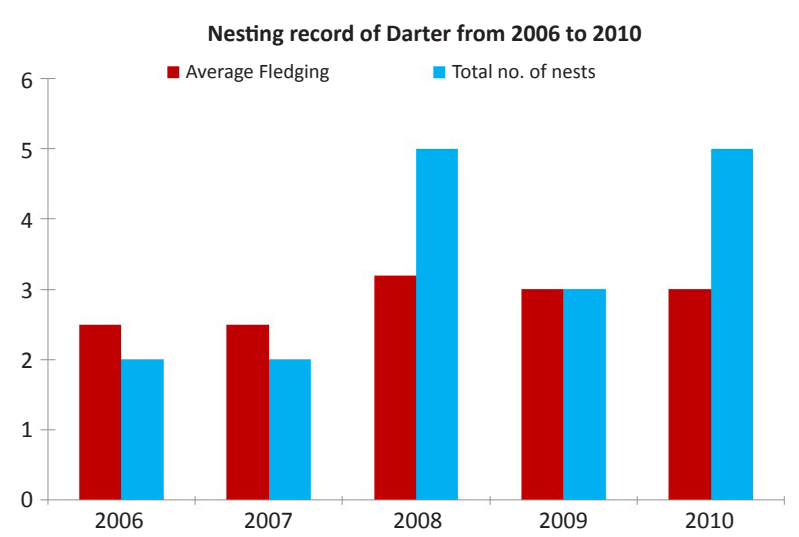

Figure 5. Average and total nests of fledging darter from 2006-2010

$\mathrm{cm}(\mathrm{n}=7)$.

A total of 23 chicks hatched, but only 19 chicks survived till fledging (Table 1 ) with a nesting success of $82.6 \%$ with 2.37 chicks fledged per nest $(n=8)$. Four chicks died out of all the hatchlings and so, chick mortality accounts for only $17.39 \%$ of the total. Nest occupation during the study hours showed female presence in $45.92 \pm 9.13 \%$ of the time, male $26.83 \pm 12.01$ $\%$ and $26.78 \pm 9.62 \%$ with both birds in attendance $(n=7)$ (Fig.3). The male played a greater role in feeding than the female $(n=6)$ during the study period (Fig. 4).

Field records and photographs of the Darter nesting in 2006 and 2007 showed two successful nests with an average of 2.5 fledgings each, five nests with 3.2 fledgings in 2008, three nests with 3.0 fledgings in 2009 and five nests with 3.0 fledgings in 2010 per nest (Fig. 5).

Nestlings reacted adversely on closer approach to the nest tree by pelting down regurgitated food and some small fish of varying length $(4-8 \mathrm{~cm})$, identified as Banded Snake-head Channa striatus and Spotfin Barb 
Table 1. Details of nestling and fledging of Darter in Yamuna Biodiversity Park in 2011

\begin{tabular}{|l|c|c|c|}
\hline Nests on & Nest codes & $\begin{array}{c}\text { No. of chicks } \\
\text { hatched }\end{array}$ & $\begin{array}{c}\text { No. of chicks } \\
\text { fledged }\end{array}$ \\
\hline Acacia in the wetland & A1N2 & 3 & 3 \\
\hline \multirow{4}{*}{$\begin{array}{l}\text { Eucalyptus trees } \\
\text { around the wetland }\end{array}$} & EN1 & 3 & 2 \\
\cline { 2 - 4 } & EN2 & 3 & 3 \\
\cline { 2 - 4 } & EN3 & 3 & 0 \\
\cline { 2 - 4 } & EN4 & 2 & 2 \\
\cline { 2 - 4 } & EN5 & 1 & 1 \\
\cline { 2 - 4 } & EN6 & 4 & 4 \\
\cline { 2 - 4 } & EN8 & 4 & 4 \\
\hline
\end{tabular}

Puntius sophore of the family Channidae and Cyprinidae respectively.

\section{Discussion}

The nest trees with $\mathrm{GBH}$ between $85 \mathrm{~cm}$ and $90 \mathrm{~cm}$ were more successful in YBP (Fig. 5). Although the clutch size of the Darter was not ascertained in this study, photographic records from 2006-2010 showed a maximum of 5 chicks which is similar to the available literature (Vestjens 1975; Ali \& Ripley 1978; Pathak et al. 2004). Nestling survival in 2011 and the preceding years show that the Darter was breeding quite successfully in YBP, as opposed to high chick mortality rates reported (Pathak et al. 2004), excepting a single incident where chick mortality resulted due to the failure to feed the chicks in one nest where the male was unable to feed the nestlings (about 25 days old) because its bill was entangled and tightly bound with a red cloth. Repeated attempts by the male and nestlings to remove it failed leading to nest abandonment by evening and subsequent death of nestlings probably in an attempt to move to the wetland. This behavior supported our findings and that of Burger et al. (1978) that although the female spent more time incubating than the male, the role of feeding nestling is done largely by the male (Fig. 4). The cloth was identified as one used commonly for worshipping and often immersed in the river Yamuna which shows that the neighboring areas outside the park are also used for foraging by some of the individuals, making it crucial that these water bodies be identified, protected and restored. In addition to the 121 ha of area close to the river Yamuna with the further proposed area of 243ha (600 acres) into the active floodplain will provide a considerably large protected area as Biodiversity Park for the safe breeding population of birds.

A gradual increase in successful nests year after year
(Fig. 5) suggests the acceptability of the habitat in terms of breeding and as a foraging ground by this species. YBP provides a suitable habitat because of the availability of abundant catchable prey-base, vegetation for roosting and nesting, and low anthropogenic disturbance leading to the optimization of nesting of Darters. There is a need to identify more sites to understand the factors responsible for nest-site selection and causes for unacceptability of available habitat for nesting. The restoration of wetlands of YBP in the active flood zone will provide more breeding and foraging grounds for the Darter as well as other sympatric species in future.

\section{CONSERVATION IMPORTANCE}

This study is important for conservation in order to understand the habitat requirements of Near Threatened species like the Darter and to use them as tools to conserve wetlands of breeding as well as foraging importance. As evident from the study the restored wetland of YBP provides a good breeding and foraging habitat. With the wetland area in Delhi reduced from 4717ha in 2002 to 2771ha in 2011 (Prasad et al. 2002; Anonymous 2011) and the existing wetlands being degraded, protected areas like the National Zoological Park (NZP), Okhla Bird Sanctuary (OBS) (Manral \& Khudsar 2013) and YBP provide a safe haven for breeding wetland birds in the urban setup. The decline in the Darter population is highly alarming as visits to NZP where 740 Darters were reported in 1987 (Li et al. 2009) and OBS (for 4hr) in August 2011 proved futile for sighting the Darter, which was also confirmed by many amateur and professional photographers and birdwatchers (R. Lal \& S. Oswal pers. comm. 2011).

Therefore, there is a need to identify and conduct detailed studies at these sites to understand the factors responsible for nest-site selection and causes for unacceptability of the available habitat for nesting. This has a huge implication on any conservation measures to be implemented and will help in policy making for wetland conservation and management in the future. The newly restored YBP in the River Yamuna floodplain provides suitable habitat because of availability of prey species, vegetation for roosting and nesting, and low disturbance leading to the optimization of nesting of Darters.

\section{REFERENCES}

Ali, S. \& S.D. Ripley (1978). Handbook of the Birds of India and Pakistan, Vol. I. Edition 2. Oxford University Press, New Delhi, India, 384pp.

Alvarenga, H.M.F. \& E. Guilherme (2003). The Anhingas (Aves: Anhingidae) from the Upper Tertiary (Miocene-Pliocene) of 
Southwestern Amazonia. Journal of Vertebrate Paleontology 23(3) 614-621; http://dx.doi.org/10.1671/1890

Anonymous (2011). National Wetland Inventory and Assessment. Ministry of Environment and Forests, India and Space Applications Centre (ISRO), Ahmedabad, India.

BirdLife International (2012). Anhinga melanogaster. In: IUCN 2013. IUCN Red List of Threatened Species. Version 2013.1. <www. iucnredlist.org>. Downloaded on 13 November 2013.

Burger, J., L.M. Miller \& D.C. Hahn (1978). Behavior and sex roles of nesting Anhingas at San Blas, Mexico. Wilson Bulletin 90(3): 359375.

Chozhiyattel, Z. (2009). Behaviour and adaptations of Little Cormorant Phalacrocorax niger and Darter Anhinga melanogaster. PhD Thesis. University of Calicut, Kerala, India.

Gopi, G.V. (2010). Nesting ecology of colonial waterbirds at Bhitarkanika Mangroves, Orissa. PhD Thesis. Saurashtra University, Gujarat, India.

Gopi, G.V. \& B. Pandav (2011). Nest space partitioning among colonia nesting waterbirds at Bhitarkanika Mangroves, India. World Journal of Zoology 6(1): 61-72.

Jha, K.K. (2012). Some breeding and ecological aspects of heronry birds at Soor Sarovar Bird Sanctuary Agra, Northern India. Asian Journal of Conservation Biology 1(1): 35-41.

Li, Z.W.D., A. Bloem, S. Delany, G. Martakis \& J.O. Quintero (2009). Status of waterbirds in Asia - Results of the Asian Waterbird Census: 1987-2007. Wetlands International, Kuala Lumpur, Malaysia.

Manral, U. \& F.A. Khudsar (2013). Assessment of wetland water quality and avian diversity of a human-modified floodplain wetland on River Yamuna. Notulae Scientia Biologicae 5(1): 25-33.
Narayanan, S.P. \& L. Vijayan (2007). Status of colonial breeding waterbirds in Kumarakom Heronry in Kerala, southern India. Podoces 2(1): 22-29; http://dx.doi.org/10.1007/s40009-012-0027-9

Niangthianhoi, S.L. \& F.A. Khudsar (2009). Assessment of bird diversity in Yamuna Biodiversity Park and in a natural wetland. Journal of Tropical Forestry 25: 42-49.

Pathak, B.J., S. Vijayan \& B.P. Pati (2004). Observations on chick mortality in Darter Anhinga melanogaster in Gir Forest. Journal of the Bombay Natural History Society 101(2): 310.

Prasad, S.N., T.V. Ramachandra, N. Ahalya, T. Sengupta, A. Kumar, A.K. Tiwari, V.S. Vijayan \& L. Vijayan (2002). Conservation of wetlands of India - a review. Tropical Ecology 43(1): 173-186.

Ramaswami, G. (2006). A comparative study of plankton assemblages in two waterbodies of the Yamuna Biodiversity Park. MSc Thesis. University of Delhi, Delhi, India.

Ryan, P.G. (2007). Diving in shallow water: the foraging ecology of darters (Aves: Anhingidae). Journal of Avian Biology 38: 507-514; http://dx.doi.org/10.1111/j.0908-8857.2007.04070.x

Tak, P.C. \& J.P. Sati (1997). Aves, pp. 699-821. In: State Fauna Series 6: Fauna of Delhi. Zoological Survey of India, Kolkata, India.

Urfi, A.J. (2006). Biodiversity conservation in an urban landscape: A case study of some important bird areas on the river Yamuna in Delhi (India), pp. 303-317. In: McNeely, J.A., T.M. MaCarthy, A. Smith. L.O. Whittaker \& E.D. Wikramanayake (eds.). Conservation Biology in Asia. Society for Conservation Biology, Asia Section and Resources Himalaya, Kathmandu, Nepal.

Vestjens, W.J.M. (1975). Breeding behaviour of the Darter at Lake Cowal, NSW. Emu 75(3): 121-131; http://dx.doi.org/10.1071/ MU9750121

\section{Errata}

Padhye, A.D., A. Jadhav, S. Sulakhe \& N. Dahanukar (2015). Sexual dimorphism in the Kudremukh Bush Frog (Anura: Rhacophoridae: Raorchestes tuberohumerus) of the Western Ghats, India, with a note on its distribution and conservation status. Journal of Threatened Taxa 7(6): 7211-7222; http://dx.doi.org/10.11609/ JoTT.04192.7211-22

In our paper (Padhye et al. 2015) there is a mistake in the voucher numbers for the two specimens used for genetic, osteological and morphometric analysis. The specimens with the voucher numbers WILDAMP-14-499 and WILD-AMP-14-500 should be assigned to voucher numbers WILD-15-AMP-594 and WILD15-AMP-595, respectively. Accordingly, the voucher numbers need to be corrected in Materials and Methods (p. 7212), subsection Material examined: $1^{\text {st }}$ and $2^{\text {nd }}$ line, subsection Osteology: $1^{\text {st }}$ and $2^{\text {nd }}$ line, subsection Genetic analysis: $2^{\text {nd }}$ and $3^{\text {rd }}$ line; Table 1 (p. 7213), rows number 1 and 2 and Table 2 (p. 7217), second row in column 2 and 4. Voucher and GenBank accession numbers for sequences generated in the study and used in molecular analysis should be as given below (Table 1 ).

Table 1. Voucher and GenBank accession numbers for sequences used in molecular analysis.

\begin{tabular}{|l|l|l|}
\hline Species & Voucher & Accession number \\
\hline Raorchestes tuberohumerus Male & WILD-15-AMP-594 & KP137387 \\
\hline Raorchestes tuberohumerus Female & WILD-15-AMP-595 & KP137388 \\
\hline
\end{tabular}

